\title{
CBCT Imaging Of A Giant Sialolith (Megalith)
}

\author{
Sajad Ahmad Buch ${ }^{1}$, Subhas G Babu², Shruthi Hegde ${ }^{3}$, Shruthi Rao ${ }^{4}$, Vidya Ajila ${ }^{5}$ \\ ${ }^{*}$ Junior Research Fellow, Oral Medicine and Radiology, Yenepoya Dental College, Yenepoya (Deemed to be University), Deralakatte, Mangalore, \\ Karnataka-India
}

${ }^{2}$ Head of the Department, Oral Medicine and Radiology, A B Shetty Memorial Institute of Dental Sciences, NITTE (Deemed to be University), Deralakatte, Mangalore, Karnataka-India

${ }^{3}$ Reader, Oral Medicine and Radiology, A B Shetty Memorial Institute of Dental Sciences, NITTE(Deemed to be University), Deralakatte, Mangalore, Karnataka-India

${ }^{4}$ Oral Medicine and Radiology, A B Shetty Memorial Institute of Dental Sciences, NITTE(Deemed to be University), Deralakatte, Mangalore, Karnataka-India

${ }^{5}$ Professor, Oral Medicine and Radiology, A B Shetty Memorial Institute of Dental Sciences, NITTE(Deemed to be University), Deralakatte, Mangalore, Karnataka-India

\footnotetext{
Received: February 22, 2019; Accepted: March 02, 2019; Published: March 11, 2019
}

*Corresponding author: Dr Sajad Ahmad Buch, Junior Research Fellow, Oral Medicine and Radiology, Yenepoya Dental College, Yenepoya University, Deralakatte, Mangalore, Karnataka-India, 575018.E-mail: buchh.sajad@gmail.com; phone no: +917899466346

\section{Description}

Background: A 25-year-old man presented to the Department of Oral Medicine and Radiology with a painful and persistent discharge under the tongue on right side of the mouth. The patient complained of repeated episodes of pain before, during and after food intake with a recent episode of fever. Panoramic radiograph showed a radio-opaque mass superimposing over right mandibular angle region (Figure 1). Cone Beam Computed Tomography (CBCT) was obtained for the description and location of the radio-opaque mass. Multiple planar images were constructed which showed a round sialolith measuring around $22 \mathrm{~mm}$ $\mathrm{x} 18 \mathrm{~mm}$, in coronal section (Figure 2) and Three-Dimensional (3D) reconstruction (Figure 3).

Key words: Sialolithiasis; sialography; cone beam computed tomography;

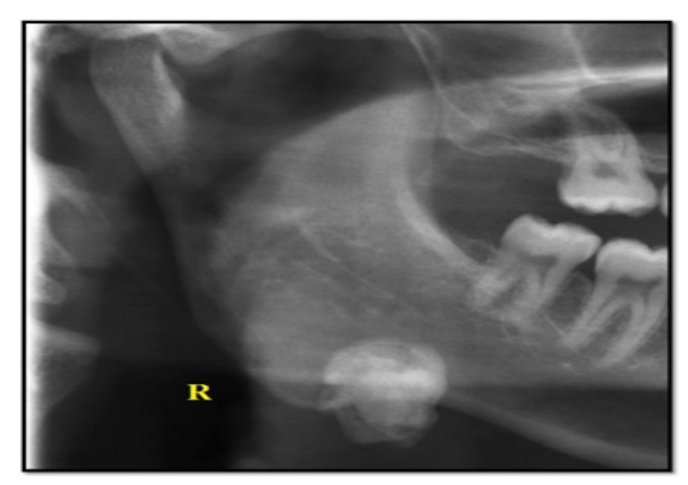

Figure 1: Cropped Panoramic radiograph showing radio-opaque mass superimposed near right mandibular angle region

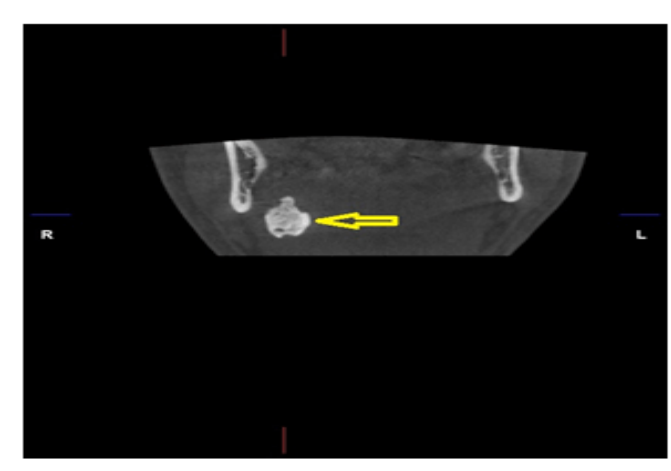

Figure 2: Coronal section of CBCT showing Right Submandibular sialolith

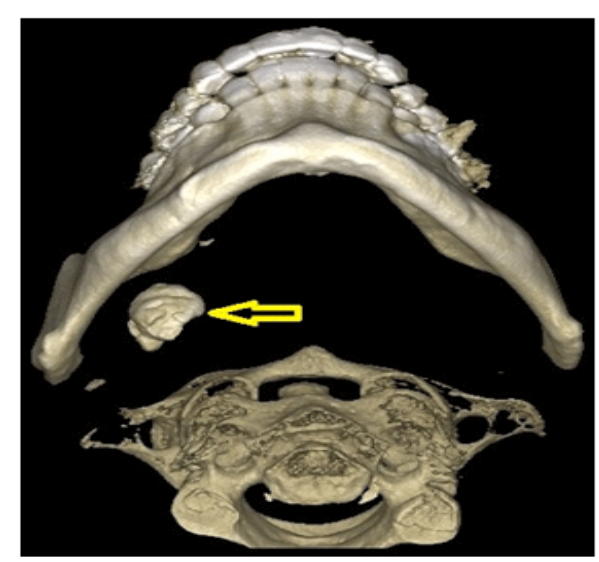

Figure 3: CBCT 3D reconstruction shows the position of giant right Submandibular Sialolith. 


\section{Discussion}

Sialolithiasis is the most common disorder of the major salivary glands characterized by the development of salivary stones (calculi or sialolith) in the ducts or the parenchyma of the affected salivary gland [1]. Sialoliths of size greater than $15 \mathrm{~mm}$ are termed as megaliths. Plain radiography has limited value in salivary gland radiology. Sialography creates exceptional contrast and allows even detection of minute stones and strictures but requires injecting contrast media into the ducts of the major salivary glands. The technique is invasive and possible failures of the technique are its limitations [2]. CBCT has definite advantage over conventional sialography in demonstrating salivary ductal system [3]. CBCT sialography can be used as the modality of choice for the demonstration of salivary ductal system and as an alternative to conventional sialography [4].

\section{References}

1. Omezli MM, Ayranci F, Sadik E, Polat ME. Case report of giant sialolith (megalith) of the Wharton's duct. Niger J Clin Pract. 2016;19(3):414417. doi: 10.4103/1119-3077.179273

2. Burke CJ, Thomas RH, Howlett D. Imaging the major salivary glands. Br J Oral Maxillofac Surg. 2011; 49(4):261-269. doi: 10.1016/j. bjoms.2010.03.002

3. Li B, Long X, Cheng Y, Wang S. Cone beam CT sialography of Stafne bone cavity. Dentomaxillofac Radiol. 2011; 40(8):519-523. doi: $10.1259 / \mathrm{dmfr} / 84472023$

4. Abdel-Wahed N, Amer ME, Abo-Taleb NSM. Assessment of the role of cone beam computed sialography in diagnosing salivary gland lesions. Imaging Sci Dent. 2013;43(1):17-23. doi: 10.5624/ isd.2013.43.1.17 